\title{
PRÁTICAS DE ISOMORFISMO E AS NORMAS INTERNACIONAIS DE CONTABILIDADE
}

\section{ISOMORPHISM PRACTICES AND INTERNATIONAL ACCOUNTING STANDARDS}

\section{DOI: http://dx.doi.org/10.21714/raunp.v9i1.948}

\section{Edson Macohon}

Doutor em Ciências Contábeis e Administração. Professor assistente da Universidade Estadual do Centro-0este - UNICENTRO.

E-mail: emacohon@yahoo.com

\author{
Andréia Dani \\ Mestre em Ciências Contábeis. Professora no Centro Universitário Cândido Rondon. \\ E-mail: andreiacarpesdani@gmail.com
}

\section{Eduardo Lavarda}

Coordenador do Programa de Doutorado em Ciências Contábeis e Administração pela Universidade Regional de Blumenau - FURB.

E-mail: elavarda@gmail.com

Envio em: Setembro de 2014

Aceite em: Março de 2017

\section{RESUMO}

Os gestores tendem a perceber as pressões ambientais e assim, gerenciam as mudanças necessárias para atender os objetivos das organizações. Estas pressões são de natureza coercitiva, normativa ou mimética. Esta pesquisa objetiva verificar se existe relação entre as práticas de isomorfismo e 0 processo de aplicação das normas internacionais de contabilidade nas indústrias de Santa Catarina. Quanto ao delineamento metodológico, a pesquisa classifica-se como descritiva realizada por meio de survey, aplicação de questionários, abordagem quantitativa. A população é caracterizada pelas 693 indústrias de Santa Catarina que possuem acima de 100 funcionários. A amostra é composta por 28 indústrias de diversos ramos de atividade que responderam os questionários. A análise da correlação demonstrou que há influência do ambiente externo sobre as organizações, o processo de convergência contábil é o principal agente motivador. As principais causas que as empresas implementaram as normas internacionais é a necessidade de estar conectada ao mercado; adequação aos clientes; pressão de competidores; e, imposição legal. Conclui-se que ocorre o predomínio do isomorfismo coercitivo, devido ao comportamento semelhante apresentado pelas empresas, bem como a forma de atuação dos profissionais em relação à adequação da nova normatização contábil.

Palavras-chave: Isomorfismo. Fatores ambientais. Normas internacionais de contabilidade.

\begin{abstract}
Managers tend to perceive environmental pressures and thus manage the changes necessary to meet the objectives of the organizations. These pressures are of coercive, normative or mimetic nature. This research aims to determine whether there is a relationship between isomorphic practices and the process of applying international accounting standards in Santa Catarina industries. Regarding the methodological design, research is classified as descriptive conducted through survey, questionnaires, quantitative approach. The population is characterized by the 693 industries of Santa Catarina that have over 100 employees. The sample consists of 28 industries from different areas of activity that answered the questionnaires. The correlation analysis showed that there is influence of the external environment on the organization, the accounting convergence process is the main motivator. The main causes that companies have implemented international standards is the need to be connected to the market; suitability to customers; pressure competitors; and legal enforcement. It is concluded that there is the predominance of coercive isomorphism, due to similar behavior presented by the companies as well as the way of acting of professionals regarding the adequacy of the new accounting regulation.
\end{abstract}

Keywords: Isomorphism. Environmental factors. International accounting standards. 


\section{INTRODUÇÃO}

Devido a fatores internos e externos das organizações brasileiras, o processo de convergência das normas de contabilidade às IFRS conduz a diversas mudanças no ambiente empresarial. Dentre estes fatores destacam-se a internacionalização dos mercados, os impactos das sucessivas crises financeiras, as exigências informacionais dos usuários, e adicionalmente, as pressões internas das organizações.

Nesse contexto, o estudo realizado por Ignacio (2010, p. 100) sobre o processo de institucionalização das normas contábeis no Brasil, contatou que "o processo encontra-se em fase de desenvolvimento de certo grau de consenso social entre os tomadores de decisões em relação ao valor da estrutura".

A partir da perspectiva institucional observa-se a análise de sistemas de crenças e de normas institucionalizadas no ambiente organizacional, tradicionalmente entendido como fluxos e intercâmbios. Nesta perspectiva, a teoria concebe as mudanças organizacionais como um processo decorrente de pressões internas e externas. Por conseguinte, ao longo do tempo, ocorre a similaridade organizacional, a influência de determinadas empresas sobre as outras (CALLADO; CALLADO; ALMEIDA, 2011).

Esta análise pode ser realizada para compreender a convergência de técnicas, sistemas gerenciais e contabilidade nas organizações (SANTOS, 2008). Granlund e Lukka (1998) consideram os três fatores da análise institucional, pressões coercitivas, normativas e os processos miméticos, para analisar a convergência das práticas de contabilidade gerencial. Os autores afirmam que o isomorfismo é baseado a partir de duas ideias centrais, os ambientes são coletivos e interconectados; e, as organizações, com objetivo de sobrevivência, devem ser sensíveis às demandas externas e expectativas de mercado.

No contexto da convergência contábil, as pressões coercitivas existem quando as organizações adotam novas regras a partir das exigências de autoridades superiores ou dominantes. O isomorfismo normativo acontece quando há o conjunto de normas e regras que regem organizações similares. O mimetismo ocorre quando, sob determinadas condições de incerteza, as organizações decidem que o caminho mais seguro é copiar o que foi feito por organizações mais bem-sucedidas (CALLADO; CALLADO; ALMEIDA, 2011).

Sob a perspectiva institucional, Burns e Scapens (2000) afirmam que a contabilidade é uma instituição dentro da empresa. As rotinas da contabilidade são formadas pelos hábitos dos indivíduos, os quais dão sentido a determinados grupos de pessoas. Assim, esta estrutura organizacional, a contabilidade, é amplamente aceita e de forma praticamente inquestionável (BURNS; SCAPENS, 2000).

Neste estágio, sob a perspectiva da Velha Economia Institucional (OIE), a institucionalização alcança a saturação, os deslocamentos do foco da mudança e o seu ritmo ao caráter temporal da instituição são estabelecidos (LAWRENCE; WINN; JENNINGS, 2001). Esta perspectiva também é analisada por Guerreiro, Frezatti e Casado (2004). Os autores afirmam que as práticas e rotinas são amplamente aceitas, desta forma tornam-se ferramentas de controle gerencial. A partir disso, a contabilidade tem forte tendência de se tornar rotinizada e institucionalizada.

De outro modo, Scapens (1994) inspirado em Dimaggio e Powell (1983), sob o arcabouço da Nova Sociologia Institucional (NIS), revela que as organizações e os campos organizacionais, ou seja, as peculiaridades internas e os desafios ambientais externos são arranjos institucionais. Assim, há a possibilidade de analisar a convergência das normas internacionais de contabilidade nas empresas brasileiras sob a ótica do isomorfismo institucional.

Para tanto, delineou-se a seguinte questão problema: Existe relação entre as práticas de isomorfismo e o processo de aplicação das normas internacionais de contabilidade nas indústrias de Santa Catarina? Para tanto, o objetivo é verificar se existe relação entre as práticas de isomorfismo e o processo de aplicação das normas internacionais de contabilidade nas indústrias de Santa Catarina.

A relevância do estudo dá-se pela compreensão do processo de aplicação das normas internacionais de contabilidade nas empresas brasileiras, fato que fora pleiteado pela classe contábil por vários anos. No entanto, há muitos desafios a serem superados, as dificuldades envolvidas e a sua resolutividade são ainda bastante desconhecidas. Esta pesquisa se caracteriza na vanguarda do conhecimento por supor que há um conjunto de variáveis internas, bem como de macroambiente, que ao mesmo tempo, mas distintamente, proporcionam facilidades e dificuldades no processo de convergência contábil.

\section{FUNDAMENTAÇÃO TEÓRICA}

\section{1 PROCESSO DE CONVERGÊNCIA CONTÁBIL NAS EMPRESAS BRASILEIRAS}

No contexto brasileiro ocorreram duas alterações relevantes na legislação societária, consideradas marcos históricos para o desenvolvimento da contabilida- 
de brasileira. As leis 6.404/76 e 11.637/07 introduziram novos conceitos e alterações que impulsionaram o processo de convergência da contabilidade brasileira às normas internacionais (VERHAGEM, 2011).

A convergência contábil no Brasil envolveu duas etapas, a primeira é a criação em 2008 do Comitê de Pronunciamentos Contábeis (CPC), com a emissão do Pronunciamento Técnico $\mathrm{n}^{\circ} 13$ - Adoção Inicial da Lei $n^{\circ}$ 11.638/07 (que engloba os CPC de números 1 a 12) e o Pronunciamento Técnico CPC 14. A segunda etapa compreendeu os CPC's de números 15 a 43 (excetuando-se o $\mathrm{n}^{\circ} 34$ ) e interpretações diversas, emitidas em 2009 (VERHAGEM, 2011).

O CPC ressalta que além da convergência internacional, outras razões impulsionaram a sua criação, a centralização na emissão de normas, bem como a representação do processo democrático na produção das informações. Esta afirmação se reporta à diversidade dos perfis profissionais que participam na construção dos pronunciamentos técnicos, como exemplo, auditores, usuários da informação, intermediários, academias, governos, entre outros.

Para Weffort (2005, p. 22) a harmonização contábil pode ocorrer de duas formas, nas práticas (harmonização de fato) que se refere a "[...] uma efetiva aplicação dos procedimentos recomendados internacionalmente nas práticas contábeis locais [...]"; e nas normas (harmonização de direito) que "[...] diz respeito, de modo simplificado, à incorporação, na legislação nacional, do conteúdo das normas internacionais, tornando determinado procedimento contábil obrigatório, permitido ou proibido".

Niyama (2005) apresentou diversas pesquisas que versam sobre o processo de harmonização internacional. O estudo constatou as principais diferenças internacionais que influenciam os relatórios financeiros, entre elas o sistema legal vigente; a influência da profissão contábil; o nível de desenvolvimento da teoria contábil; o tipo de regime e estrutura das demonstrações contábeis; o tipo de empresas; o nível de exigência; o nível de inflação; a vinculação econômica e política com outros países; a cultura; o ambiente social; e, o sistema político.

Entretanto, Santos e Calixto (2010, p. 3) tratam a convergência às normas internacionais como um salto de competitividade para as empresas brasileiras: "[...] o interesse pelos impactos do IFRS reflete a expectativa de que sua adoção no Brasil, tal como ocorre em outros países, trará para as empresas benefícios de liquidez, menor custo de capital e maior valorização e atratividade no mercado".
Antunes, Antunes e Penteado (2007) complementam que a adoção das normas internacionais está associada a benefícios econômicos concretos. Como exemplo, a maior atração de investimentos, devido à confiabilidade e comparabilidade das informações contábeis. Chairas e Radianto (2001) especificam os principais benefícios do processo de harmonização contábil. Dentre eles, mencionam também a comparabilidade, a compreensão da informação contábil, a disseminação de práticas e normas contábeis de alta qualidade, a provisão de baixos custos financeiros na elaboração e adoção dos padrões contábeis para países de limitados recursos financeiros e a remoção de barreiras ao fluxo de capitais internacionais.

McManaus (2009, p. 18) vai além, aponta que no Brasil, o processo de convergência contábil afetou mais do que apenas "[...] as demonstrações financeiras, que algumas exigências do IFRS, afetaram outras áreas que não a contábil e poderiam fazer com que a administração mudasse suas práticas comerciais".

Lemes e Carvalho (2004) sob a perspectiva institucional defendem que o processo de convergência das normas contábeis sofre influência de fatores ambientais externos, bem como depende do envolvimento do poder coercitivo para a sua concretização.

\subsection{ISOMORFISMO E AMBIENTE INSTITUCIONAL}

DiMaggio e Powell (1983) conceberam, com base nas pesquisas iniciais de Meyer e Rowan (1977), a perspectiva neo-institucional, qual foca o problema do isomorfismo institucional no campo organizacional (MCKINLEY; MONE, 2003). Caldas e Wood Jr. $(1999$, p. 295) tratam o isomorfismo como um "processo que leva organizações em determinado setor a parecer-se com outras, com as quais partilha as mesmas condições ambientais. [...] Uma vez que passem pelo processo de institucionalização, porém, ocorre uma tendência para a homogeneização".

De acordo com Passalongo, Ichikawa e Reis (2004), o isomorfismo institucional é o surgimento de uma estrutura e abordagens comuns entre as organizações do mesmo setor. Os relacionamentos interorganizacionais possuem forças que fazem com que as organizações de um mesmo setor se pareçam entre si.

Freitas e Guimarães (2005) conceituam o isomorfismo como o resultado das pressões competitivas que conduzem as organizações a adotar a maneira mais adequada de sobrevivência. Entende-se, portanto, que 
o ambiente isomórfico pode ser caracterizado como a semelhança de procedimentos realizados pelas organizações. Por exemplo, devido à competitividade do setor, as organizações buscam em outras, modelos e formas de gestão para acompanhar o desenvolvimento do mercado.

No que concerne ao reconhecimento organizacional às novas práticas da contabilidade, Freitas e Guimarães (2005) destacam o isomorfismo como um mecanismo de legitimidade para a organização. Este é um exemplo do resultado da institucionalização, ou seja, quando regimes ou retóricas dominantes preconizaram práticas, regras, tecnologias, ou uma combinação institucionalizada (LEBLEBICI et al., 1991).

Assim, a instituição alcança o estágio de legitimação, as práticas são difundidas entre a maioria dos membros que participam do campo. Neste estágio, a estabilidade prepondera, no entanto, a organização passa a ter características de resistência, bem como as práticas legitimadas passam a influenciar a instituição (LAWRENCE; WINN; JENNINGS, 2001).

Quando se trata do fenômeno institucional da contabilidade em um ambiente isomórfico, Augusto (2007) relaciona a institucionalização de normas e regras comuns em empresas do mesmo ramo de atuação. O autor identificou dois tipos de ambientes isomórficos que podem ser considerados preponderantes à competitividade organizacional, o ambiente interno e o ambiente externo.

\subsubsection{AMBIENTE INTERNO}

A abordagem interna considera as organizações que enfrentam o mesmo ambiente. Para Augusto (2007) é possível identificar diferenças entre as organizações em suas reações a pressões similares do ambiente institucional. Esta abordagem dedica pouca atenção à especificação das características e condições do ambiente institucional, mas considera que as diferentes reações ao ambiente são, na maioria, afetadas por fatores não organizacionais (AUGUSTO, 2007).

Para tanto, concebe-se a teoria neo-institucional, a qual analisa os níveis micro e macro das organizações (MCKINLEY; MONE, 2003). Na concepção funcionalista, Mangi (2004, p. 3) considera as relações de causa e efeito que o ambiente macro exerce nas organizações: "Os primeiros movimentos de reação aos postulados racionalistas da escola clássica de administração buscavam um enfoque mais relacional na análise do ambiente interno das organizações".

No entendimento de Augusto (2007), a análise macroinstitucional pode gerar variabilidade nas estratégias organizacionais. Desta forma, a variabilidade passa a ser representada por uma diferenciação e não pelo isomorfismo. Em consequência disso, o autor destaca o processo institucional interno para analisar o isomorfismo.

\subsubsection{AMBIENTE EXTERNO}

O foco da abordagem externa é a identificação dos atributos do ambiente institucional, que podem gerar diferenças nas estruturas e processos das organizações. Esta abordagem considera o ambiente institucional como inconsistente e conflitante, composto de um conjunto de múltiplas instituições que impõem diferentes demandas e expectativas (AUGUSTO, 2007)

O ambiente externo também é afetado pela globalização, que é considerada por Augusto (2007) uma variável potencializadora das pressões isomórficas. Como exemplo, a dinâmica competitiva global que pressiona as empresas às novas condições de mercado. A tempo, as empresas decidem copiar práticas utilizadas por organizações de sucesso.

Desta forma, as pressões externas interferem os processos organizacionais. As empresas reagem a estas pressões de diferentes maneiras. A análise isomórfica contribui para a compreensão mais aprofundada da relação entre as variáveis macroambientes e o processo de mudança organizacional.

\subsubsection{TIPOS DE ISOMORFISMO}

O isomorfismo se caracteriza de três formas: coercitivo, normativo e mimético.

a) Isomorfismo coercitivo

$\mathrm{O}$ isomorfismo coercitivo está relacionado com o ambiente externo. Freitas e Guimarães (2005) exemplificam, a atuação do governo sobre as organizações, por meio de leis, normas e exigências fiscais, interfere os padrões de produção, comportamento organizacional e relações com consumidores.

Coraiola e Silva (2007) se reportam ao isomorfismo coercitivo como o qual estabelece as práticas organizacionais. Este cenário ocorre quando há relações de dependência, por exemplo, demandas de informações de órgãos estatais às empresas privadas (MCKINLEY; MONE, 2003). 
b) Isomorfismo normativo

A normatização ocorre quando, por exemplo, um órgão profissional estabelece padrões de qualidade a determinados processos organizacionais (MCKINLEY; MONE, 2003). O isomorfismo normativo é atribuído à profissionalização (CORAIOLA; SILVA, 2007).

$\mathrm{O}$ isomorfismo normativo é o conjunto de normas e regras que regem as instituições. Devido a sua função altamente normativa, o ambiente da contabilidade pode ser analisado sob esta perspectiva.

c) Isomorfismo mimético

Para Mckinley e Mone (2003) o isomorfismo mimético ocorre quando uma organização copia o que foi feito por organizações bem-sucedidas. Freitas e Guimarães (2005) discorrem sobre modelos políticos para entender a predominância dos tipos de isomorfismo em diferentes circunstâncias. As sociedades democráticas, com maiores ofertas competitivas de bens e serviços, tendem a processos miméticos e normativos. Enquanto em sociedades de tradição mais autoritária, a tendência é a predominância do isomorfismo coercitivo (FREITAS; GUIMARÃES, 2005).

\section{PROCEDIMENTOS METODOLÓGICOS}

A pesquisa classifica-se em relação aos procedimentos metodológicos como descritiva, realizada por meio de survey, com abordagem quantitativa. A pesquisa descritiva concebe a descrição de diferentes práticas contábeis (SCAPENS, 1990) ou a semelhança destas práticas em diferentes empresas. Tais estudos podem ser úteis para explorar o uso de modernas ou tradicionais práticas contábeis. A pesquisa descritiva pode oferecer a possibilidade de determinar a prática mais comum adotada pelas empresas (RYAN; SCAPENS; THEOBALD, 2002).

Para desvendar a natureza da objetividade dos fatos e a coerência analítica, o método utilizado nesta pesquisa é indutivo, o qual busca retratar a realidade do fenômeno a partir das relações de causa-e-efeito entre variáveis.

A população inicial desta pesquisa é caracterizada pelas 693 indústrias de Santa Catarina que possuem acima de 100 funcionários, listadas no catálogo disponibilizado pela FIESC. Este catálogo apresenta as informações completas sobre o setor industrial de Santa Catarina, nas versões on-line e impresso. $\mathrm{O}$ acesso às informações cadastrais das empresas integrantes da amostra foi obtido a partir do sítio da FIESC (http:// www.fiescnet.com.br/guiawebsc).

Como justificativa ao critério de seleção da população da pesquisa, salienta-se que o sistema FIESC, representa as indústrias catarinenses, composta por mais de 38 mil empresas, nas quais trabalham mais 670 mil pessoas, responsável por um terço da riqueza gerada no estado. A amostra da pesquisa é composta por 28 indústrias de diversos ramos de atividade que responderam os questionários.

$\mathrm{O}$ instrumento da pesquisa foi elaborado a partir dos estudos de Santos (2008) e Verhagem (2011). O estudo de Santos (2008) apresenta um diagnóstico institucional dos fatores que concorrem para a prática do isomorfismo, através de um questionário fechado formado por 12 blocos de questões. Deste estudo foram selecionadas as questões relacionadas à condição ambiental.

A pesquisa de Verhagem (2011) fornece informações dos impactos do processo de implementação das normas internacionais no Brasil. Assim, possibilitou a identificação dos pronunciamentos técnicos que tiveram maior impacto nas empresas.

$\mathrm{O}$ instrumento de pesquisa, 40 questões fechadas, é formado por quatro blocos de questões, dois blocos relacionados ao isomorfismo foram adaptados a partir do estudo de Santos (2008); e, outros dois blocos relacionados ao processo de convergência contábil foram elaborados a partir do estudo de Verhagem (2011).

De acordo com a Comissão Nacional de Ética em Pesquisa (CONEP), o procedimento metodológico para coleta dos dados ocorreu, primeiramente, via contato por telefone com os responsáveis pela contabilidade de cada empresa. Na sequência, os questionários foram enviados por e-mails. $\mathrm{O}$ instrumento de pesquisa foi elaborado por meio do software FormSite.

A análise dos dados dá-se por meio da estatística descritiva, e, por conseguinte aplicação de correlação entre as variáveis que representam as práticas isomórficas e as normas internacionais de contabilidade.

\section{ANÁLISE E DESCRIÇÃO DOS DADOS}

\subsection{PERFIL DOS RESPONDENTES}

A Tabela 1 apresenta a descrição das empresas que compõem a amostra da pesquisa, por meio da relação de frequências. 
TABELA 1: OCUPAÇÃO PROFISSIONAL DOS RESPONDENTES

\begin{tabular}{l|c|c|c}
\hline Ocupação & Frequência Absoluta & Frequência Relativa (\%) & Frequência Acumulada \\
\hline Controller & 09 & $61 \%$ & 09 \\
\hline Contador & 17 & $32 \%$ & 26 \\
\hline Outra Área & 02 & $07 \%$ & 28 \\
\hline Total & $\mathbf{2 8}$ & $\mathbf{1 0 0} \%$ & - \\
\hline
\end{tabular}

Fonte: Dados da pesquisa.

Na Tabela 1, verifica-se que $61 \%$ dos participantes da pesquisa são contadores e $32 \%$ controllers. Desta forma, verifica-se a representatividade qualitativa dos respondentes, os quais participaram do processo de aplicação das normas internacionais de contabilidade.

\subsection{CONDIÇÃO AMBIENTAL} MERCADOLÓGICA DA ORGANIZAÇÃO

A Tabela 2 apresenta as características referentes à condição ambiental mercadológica.

TABELA 2: CONDIÇÃO AMBIENTAL MERCADOLÓGICA DA ORGANIZAÇÃO

\begin{tabular}{|c|c|c|c|}
\hline Ambiente & $\begin{array}{c}\text { Frequência } \\
\text { Absoluta }\end{array}$ & $\begin{array}{l}\text { Frequência } \\
\text { Relativa (\%) }\end{array}$ & $\begin{array}{l}\text { Frequência } \\
\text { Acumulada }\end{array}$ \\
\hline $\begin{array}{l}\text { Ambiente estável e previsível: as mudanças ocorrem lentamente, } \\
\text { e o padrão de mudança é previsível }\end{array}$ & 07 & $25 \%$ & 07 \\
\hline $\begin{array}{l}\text { Ambiente estável e imprevisível: as mudanças desenvolvem-se } \\
\text { lentamente, mas o padrão de mudança é imprevisível }\end{array}$ & 04 & $14 \%$ & 11 \\
\hline $\begin{array}{l}\text { Ambiente instável e previsível: apresenta uma frequên-cia de } \\
\text { mudança mais elevada, mas seu padrão é previsível }\end{array}$ & 11 & $39 \%$ & 22 \\
\hline $\begin{array}{l}\text { Ambiente instável e imprevisível: ambiente que muda com muita } \\
\text { frequência e de forma irregular }\end{array}$ & 06 & $21 \%$ & 28 \\
\hline Total & 28 & $100 \%$ & - \\
\hline
\end{tabular}

Fonte: Dados da pesquisa.

A Tabela 2 demonstra os tipos de ambiente que as organizações podem enfrentar para convergir às normas internacionais de contabilidade. A estrutura desta tabela segue o preconizado por McKinley e Mone (2003) os quais afirmam que as mudanças seguem um processo decorrente de pressões internas e externas, mas que, ao longo do tempo, ocorre à similaridade organizacional.

Conforme exposto na Tabela 2, verificou-se que a maior parte das empresas enfrenta um ambiente instável, mas previsível. Desta forma, percebe-se que o ambiente sugere incertezas. Callado, Callado e Al- meida (2011) se reportam ao isomorfismo mimético quando há incertezas ambientais. Assim, a condição ambiental mercadológica das organizações é classificada como mimética.

\subsection{IMPACTO DOS PRONUNCIAMENTOS TÉCNICOS NA EMPRESA}

A Tabela 3 apresenta os elementos e pronunciamentos contábeis abordados por Verhagem (2011), bem como a média e o desvio padrão referentes às indicações dos respondentes. 
TABELA 3: IMPACTO DOS PRONUNCIAMENTOS CONTÁBEIS NA EMPRESA

\begin{tabular}{l|c|c}
\hline CPC's & Média & Desvio Padrão \\
\hline Aumento da evidenciação das informações contábeis e financeiras & 3,714 & 0,959 \\
\hline Reversão de reserva de reavaliação (CPC 13) & 2,357 & 0,785 \\
\hline As novas demonstrações DRA e DVA (CPC 09) & 3,142 & 1,081 \\
\hline O custo atribuído e correção monetária & 2,25 & 0,910 \\
\hline Teste de Redução a valor recuperável de ativos (CPC 01) & 2,857 & 0,887 \\
\hline Mudança na taxa de cambio (CPC 02) & 2,0 & 0,620 \\
\hline Reclassificação do ativo diferido (CPC 04) & 2,214 & 0,663 \\
\hline Instrumentos financeiros (CPC 38,039 e 40) & 2,321 & 0,770 \\
\hline Reconhecimento de receita (CPC 30) & 3,321 & 0,892 \\
\hline Avaliação da vida útil dos ativos (CPC 27) & 3,642 & 0,841 \\
\hline Relatório (informações) por segmento (CPC 22) & 2,392 & 0,75 \\
\hline Mensuração pelo valor justo de alguns ativos e passivos & 3,035 & 0,829 \\
\hline Ajuste a valor presente (CPC 12) & 3,142 & 0,867 \\
\hline Revisão da vida útil dos ativos anualmente (CPC 27) & 3,107 & 0,971 \\
\hline Reconhecimento e divulgação do plano de opção de ações (CPC 10) & 2,464 & 0,798 \\
\hline Apresentação do balanço das empresas controladas no exterior como filiais & 2,428 & 0,734 \\
\hline
\end{tabular}

Legenda: Muito Baixo (1), Baixo (2), Indiferente (3), Alto (4), Muito Alto (5).

Fonte: Dados da pesquisa.

A Tabela 3 demonstra os principais pronunciamentos contábeis que impactaram o processo de convergência contábil nas empresas analisadas. Os elementos e pronunciamentos contábeis que tiveram maior impacto no processo de convergência foram o aumento da evidenciação das informações contábeis e financeiras - avaliação (indiferente a alto); a avaliação da vida útil dos ativos (CPC 27) - avaliação (indiferente a alto); o reconhecimento de receita (CPC 30) - avaliação (indiferente a alto); as novas demonstrações DRA e DVA (CPC 09) - avaliação (indiferente); e, o ajuste a valor presente (CPC 12) - avaliação (indiferente). Estes elementos e pronunciamentos contábeis apresentaram médias acima de 3,1 - avaliação (indiferente) e desvios padrão relativamente baixos.
Assim, entende-se que de forma geral, os pronunciamentos contábeis não tiveram impactos significativos no processo de convergência contábil das empresas. Esta constatação não corrobora integralmente com McManaus (2009), o qual afirma que o processo de convergência contábil impactou outras áreas além da contabilidade.

\subsection{IMPACTO DOS PRONUNCIAMENTOS NAS DEMONSTRAÇÕES CONTÁBEIS}

A Tabela 4 apresenta as causas da aplicação das normas internacionais de contabilidade nas empresas em estudo.

TABELA 4: CAUSAS DA APLICAÇÃO DAS NORMAS CONTÁBEIS NA ORGANIZAÇÃO

\begin{tabular}{|c|c|c|}
\hline Causas da aplicação & Média & Desvio Padrão \\
\hline Pressão de grupos externos interessados na organização & 2,464 & 0,926 \\
\hline Relação de dependência com os grupos externos interessados na organização & 2,892 & 0,844 \\
\hline O conteúdo das praticas são consistentes com os objetivos da organização & 2,535 & 0,903 \\
\hline $\begin{array}{l}\text { O conteúdo das praticas tem como objetivo restringir (impor limites) as ações } \\
\text { da organização }\end{array}$ & 2,178 & 0,658 \\
\hline As práticas são impostas de forma obrigatória à organização & 3,75 & 0,607 \\
\hline $\begin{array}{l}\text { Essas práticas são propagadas naturalmente dentro do setor econômico de- } \\
\text { vido ao seu conteúdo }\end{array}$ & 2,821 & 0,846 \\
\hline
\end{tabular}




\begin{tabular}{l|c|c}
\hline Causas da aplicação & Média & Desvio Padrão \\
\hline $\begin{array}{l}\text { A organização esta conectada ao mercado, às necessidades dos clientes, } \\
\text { aos competidores, etc. }\end{array}$ & 3,964 & 0,489 \\
\hline Por imposição legal & 3,928 & 0,821 \\
\hline
\end{tabular}

Legenda: Muito Baixo (1), Baixo (2), Indiferente (3), Alto (4), Muito Alto (5).

Fonte: Dados da pesquisa.

Os respondentes indicaram como as principais causas da aplicação das normas internacionais de contabilidade quando a organização está conectada ao mercado, às necessidades dos clientes, aos competidores, etc., média 3,964 - avaliação (alto); por imposição legal, média 3,928 - avaliação (alto); e, as práticas são impostas de forma obrigatória à organização, média 3,75 - avaliação (alto). Os respectivos desvios padrão são relativamente baixos.

Estes resultados conferem aos de Mckinley e Mone (2003) e Passalongo, Ichikawa e Reis (2004), quando afirmam que o isomorfismo coercitivo ocorre em casos de mudanças organizacionais provocadas por pressões governamentais. Estas pressões institucionais, as normas internacionais de contabilidade, afetam o ambiente e o desempenho organizacional das empresas.

\subsection{ATUAÇÃO FRENTE AO PROCESSO DE CONVERGÊNCIA CONTÁBIL}

A Tabela 5 demonstra a atuação do profissional contábil no processo de convergência contábil.

TABELA 5: ATUAÇÃO FRENTE AO PROCESSO DE CONVERGÊNCIA CONTÁBIL

\begin{tabular}{l|c|c}
\hline Postura do profissional & Média & Desvio Padrão \\
\hline $\begin{array}{l}\text { Aceito mudanças, pois representam os sistemas e as métricas que devem ser } \\
\text { utilizadas nesta atividade econômica. }\end{array}$ & 3,75 & 0,571 \\
\hline $\begin{array}{l}\text { Aceito as mudanças, pois é o sistema utilizado na maioria das organizações } \\
\text { deste setor econômico. }\end{array}$ & 3,642 & 0,698 \\
\hline $\begin{array}{l}\text { Aceito as mudanças, pois é o sistema que trará benefícios para a organização, } \\
\text { já que a gestão da organização busca estrategicamente utilizar as melhores } \\
\text { práticas. }\end{array}$ & 3,857 & 0,5 \\
\hline $\begin{array}{l}\text { Adoto parcialmente as práticas do processo de convergência, faço o } \\
\text { estritamente necessário para acomodar as necessidades legais da organização. }\end{array}$ & 3,142 & 1 \\
\hline $\begin{array}{l}\text { Mantenho minhas discordâncias e restrições quanto às mudanças em silêncio, } \\
\text { quando auditado ou questionado faço comentários e relatórios só para manter } \\
\text { os questionamentos. }\end{array}$ & 2,107 & 0,732 \\
\hline $\begin{array}{l}\text { lgnoro as demandas relacionadas às mudanças, o risco de ser punido por não } \\
\text { utilizá-las é mínimo, ou as consequências de desconsiderá-las são pe-quenas } \\
\text { e administráveis. }\end{array}$ & 1,607 & 0,563 \\
\hline $\begin{array}{l}\text { Negocio com os gestores a relação custo beneficio de algumas práticas do } \\
\text { processo de convergência contábil. }\end{array}$ & 3,642 \\
\hline $\begin{array}{l}\text { Contexto as pressões exercidas pelas mudanças, em minha opinião existem } \\
\text { bases razoáveis para a sua não aplicabilidade na atividade da empresa. }\end{array}$ & 3,142 & 0,602 \\
\hline
\end{tabular}

Legenda: Discordo Totalmente (1), Discordo (2), Indiferente (3), Concordo (4), Concordo Totalmente (5).

Fonte: Dados da pesquisa.

A Tabela 5 demonstra o papel do profissional contábil frente às novas normas. A alternativa que teve a maior média 3,857 é "Aceito as mudanças, pois é o sistema que trará benefícios para a organização, já que a gestão da organização busca estrategicamente utilizar as melhores práticas". Mckinley e Mone (2003) ressaltam que as mudanças organizacionais ocorrem como formas de facilitar o trabalho das organizações. Augusto (2007) revela que o macroambiente pode transformar as estratégias organizacionais. Assim, entende-se que a convergência da empresa às normas internacionais é uma estratégia de mercado. 
A alternativa com a segunda maior média 3,75 é "Aceito mudanças, pois representam os sistemas e as métricas que devem ser utilizadas nesta atividade econômica". Esta frequência de indicações revela a presença do isomorfismo coercitivo no processo de convergência contábil. Segundo Coraiola e Silva (2007), o ambiente coercitivo estabelece as práticas organizacionais.

\subsection{CORRELAÇÃO DE SPEARMAN}

Na sequência, a análise dos dados por meio da correlação entre as variáveis CIN (causas da implementação das normas), PPC (postura do profissional contábil) e a variável PCA (pronunciamentos contábeis aplicados pelas empresas). A Tabela 6 demonstra a correlação entre as variáveis investigadas.

TABELA 6: CORRELAÇÃO DE SPEARMAN

\begin{tabular}{c|c|c|c}
\hline \multicolumn{4}{|c}{ Correlação } \\
\hline & \multicolumn{3}{|c}{ Coeficiente de Correlação } \\
\hline Variáveis & $\boldsymbol{P C A}$ & $\boldsymbol{C I N}$ & $\boldsymbol{P P C}$ \\
\hline $\boldsymbol{P C A}$ & 1,000 &, $\mathbf{4 1 7}\left(^{*}\right.$ &,- 177 \\
\hline CIN &, $\mathbf{4 1 7}\left(^{*}\right)$ & 1,000 &, 038 \\
\hline PPC &,- 177 &, 038 & 1,000 \\
\hline
\end{tabular}

*Significante ao nível de $5 \%$.

Legenda: CIN-causas da implementação das normas; PPC-postura do profissional contábil; PCA-pronunciamentos contábeis aplicados pelas empresas.

Fonte: Dados da pesquisa.

A pesquisa procura explicar uma possível relação entre as variáveis que representam as práticas isomórficas (CIN, PPC) e a variável relativa às normas internacionais de contabilidade (PCA). A Tabela 6 revela que as variáveis PCA e CIN são estatisticamente significativas, ao nível de $0,05 \%$. Para tanto, infere-se que a relação positiva representa a aplicação dos pronunciamentos contábeis e seus reflexos são motivados por fatores coercitivos (causas da implementação). Isto se deve às pressões ocorridas pelo ambiente legal da contabilidade. Esta constatação corrobora com McKinley e Mone (2003), o isomorfismo coercitivo ocorre quando há relações de dependência, por exemplo, exigências de órgãos estatais a empresas privadas.

\section{CONCLUSÕES}

Esta pesquisa teve como objetivo verificar se existe relação entre as práticas de isomorfismo e o processo de aplicação das normas internacionais de contabilidade nas indústrias catarinenses. A principal constatação é que as abordagens isomórficas podem representar o ambiente organizacional das empresas no processo de convergência contábil.

Verificou-se inicialmente que os contadores possuem uma visão predominantemente financeira das pressões advindas do processo de convergência contábil. Os respondentes consideram o ambiente instável e previsível. De acordo com Mckinley e Mone (2003), Passalongo, Ichikawa e Reis (2004) e Callado, Callado e Almeida (2011), o resultado desta pesquisa demonstra a influência do ambiente externo nas organizações, ou seja, órgãos reguladores exercem pressão coercitiva às empresas.

Conforme Freitas e Guimarães (2005) as principais causas que levaram as empresas convergir às normas internacionais de contabilidade revelam o caráter coercitivo do fenômeno. A atuação do governo sobre as organizações, por meio de leis, normas e exigências fiscais, interfere comportamento organizacional.

Por último, verificou-se a atuação do profissional contábil frente às exigências do processo de convergência. A pesquisa constatou que as mudanças são aceitas, os contadores e controllers reconhecem que as mudanças trarão benefícios para a organização.

A pesquisa vislumbrou que há o predomínio do isomorfismo coercitivo no processo de convergência contábil nas indústrias catarinenses. O resultado da correlação é significativo entre as variáveis isomórficas e as normas internacionais de contabilidade. Assim, a aplicação das normas internacionais de contabilidade pelas empresas analisadas é um fenômeno 
ambiental coercitivo.

Para a realização de pesquisas futuras, sugere-se aprofundar o conhecimento sobre o processo de convergência contábil com a inclusão de variáveis ins- titucionais, fatores ambientais externos, como exemplo, crises financeiras. Sugere-se também, estudos comparativos entre empresas de diferentes setores de atuação e localização geográfica.

\section{REFERÊNCIAS}

ANTUNES, J.; ANTUNES, G. M. B.; PENTEADO, I. M. A convergência contábil brasileira e a adoção das normas internacionais de contabilidade: o IFRS 1. In: SEMINÁRIOS EM ADMINISTRAÇÃO FEA-USP, 10., 2007, São Paulo. Anais ... São Paulo: USP, 2007. Disponível em: <http://www.ead.fea.usp.br/semead/10semead/ sistema/resultado/trabalhosPDF/30.pdf>. Acesso em: 01 mar. 2012.

AUGUSTO, P. O. M. Estratégia e Ambiente: contribuições da teoria institucional. Rio de Janeiro: Congresso Enanpad, 2007.

BURNS, J.; SCAPENS, R. W. Conceptualizing management accounting change: an institutional framework. In: Management Accounting Research, 2000.

CALLADO, A. A. C.; CALLADO, A. L. C.; ALMEIDA, M. J. Isomorfismo e práticas de gestão de custos: um estudo empírico entre empresas do porto digital a partir da teoria institucional. In: ANPCONT - Associação dos Programas de pós-graduação em Ciências Contábeis. Anais... ANPCONT, Vitoria, 2011.

CHAIRAS, I. Y., RADIANTO, W. R. D. Accounting Harmonization in ASEAN: the process, benefits and obstacles. International Accounting and Finance, Master Thesis no. 2001:05, Göteborg University.

CORAIOLA, D. M.; SILVA, C. L. M. A influência dos discursos no isomorfismo organizacional: as mudanças gráficas em jornais brasileiros. Rio de Janeiro: Congresso Enanpad, 2007.

DIMAGGIO, P. J.; POWELL, W. W. The iron cage revisited: institutional isomorphism and collective rationality in organizational fields. In: American Sociological Review, v. 48, p. 147-160, 1983.

FREITAS, C. A. S.; GUIMARÃES, T. A. Isomorfismo, institucionalização e legitimidade: a atividade de auditoria operacional no tribunal de contas da união. Brasília: Congresso Enanpad, 2005.

GRANLUND, M.; LUKKA, K. It is a small world of management accounting practices. In: Journal of Management Accounting Research, 153-179, 1998.

GUERREIRO, R.; FREZATTI, F.; CASADO, T. Em busca do entendimento da formação dos hábitos, rotinas e instituições da contabilidade gerencial. São Paulo: Congresso Universidade de São Paulo, 2004.

IGNACIO, S. S. Avaliação da conexão entre as normas e praticas contábeis e fiscais no Brasil. 2010. 123f. Dissertação (Mestrado em Ciências Contábeis) FEA USP - Universidade de São Paulo, Ribeirão Preto, 2010.

LAWRENCE, T. B.; WINN M. I.; JENNINGS, P. D. The temporal dynamics of institutionalization. Academy of Management. The Academy of Management Review. v. 26. n. 4, 624-644, 2001.

LEBLEBICI, H.; SALANCIK, G. R.; COPAY, A.; KING, T. Institutional change and the transformation of interorganizational fields: an organizational history of the U.S. radio broadcasting industry. Administrative Science Quarterly., V. 36, p.333-363, 1991. 
LEMES, S.; CARVALHO, L. N. G. Efeito da convergência das normas contábeis brasileiras para as normas internacionais do IASB. São Paulo: Congresso USP de Controladoria e Contabilidade, 2004.

MCKINLEY, W.; MONE, M. Organization theory. Oxford University Press, USA. 2003.

PASSALONGO, C.; ICHIKAWA, E. Y.; REIS, L. G. Contribuições da teoria institucional para os estudos organizacionais: o caso da universidade de Londrina. Revista de Negócios. Blumenau, v. 9, n. 1, p. 19-26, jan/ mar, 2004.

RYAN, B.; SCAPENS, R. W.; THEOBALD, M. Research method and methodology in finance and accounting. 2002.

SANTOS, A. R. Diagnostico institucional dos fatores que concorrem para o isomorfismo das práticas de contabilidade gerencial utilizadas pelas organizações do setor elétrico brasileiro. 2008. 246 f. Dissertação (Mestrado em Ciências Contábeis) UFPR - Universidade Federal do Paraná, Curitiba, 2008.

SANTOS, E. S.; CALIXTO, L. Impactos do início da harmonização contábil internacional (Lei 11.638/07) nos resultados das empresas abertas. RAE-Eletrônica, v. 9, n. 1, Art. 5, jan./jun., 2010. Disponível em: < http:// www.scielo.br/pdf/raeel/v9n1/v9n1a6.pdf >.

SCAPENS, R. W. Researching management accounting practice: the role of case study methods. The British Accounting Review, v. 22, n. 3, p. 259-281, 1990.

SCAPENS, R. W. Never mind the gap: towards an institutional perspective on management accounting practice. In: Management Accounting Research, v. 5, n. 3, p. 301-321, 1994.

WEFFORT, E. F. J. O Brasil e a harmonização contábil internacional: influências dos sistemas jurídicos e educacional, da cultura e do mercado. São Paulo: Atlas, 2005.

VERHAGEM, José Ari. Análise do impacto da implementação das normas internacionais de contabilidade no Brasil: estudo de caso em uma grande empresa. 2011. 126 f. Dissertação (Mestrado em Ciências Contábeis) - Programa de Pós-Graduação em Ciências Contábeis da Universidade Regional de Blumenau, Blumenau, 2011. 